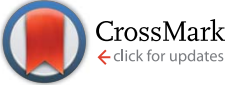

Cite this: RSC Adv., 2017, 7, 14395

\title{
Copper loaded on activated carbon as an efficient adsorbent for removal of methylene blue
}

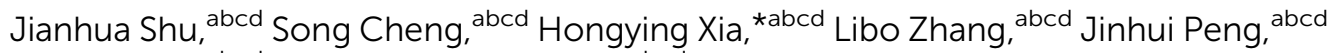 \\ Chunyang Li ${ }^{\text {abcd }}$ and Shengzhou Zhang ${ }^{\text {abcd }}$
}

Copper loaded activated carbon (Cu-AC) was prepared by impregnating it with cupric nitrate followed by microwave heating and then used for removing dyes in wastewater. The CU-AC was thoroughly characterized by $\mathrm{N}_{2}$ adsorption and desorption isotherms, SEM, EDS, XRD, XPS, FT-IR, and Raman. It was proven that cupric nitrate was successfully loaded onto activated carbon with the resulting formation of copper, copper oxide, and cuprous oxide. The $\mathrm{Cu}-\mathrm{AC}$ was used to treat five kinds of dyes in wastewaters (Rhodamine B, MB, Amaranth, Congo red, and Eosin-Y). Comparing the adsorption capacity of these five dye wastewaters, it was proven that copper and copper oxides have photocatalytic degradation ability that can improve dye removal efficiency. Experimental adsorption data of MB were fit using several kinetic and isotherm models. Kinetic studies indicated that a pseudo-second order is the most suitable model for the adsorption process with a correlation coefficient of $R^{2}>0.999$. The equilibrium adsorption data of MB showed that it followed the Langmuir isotherm; the Langmuir maximum adsorption capacity was $373 \mathrm{mg} \mathrm{g}^{-1}$. Compared with ordinary activated carbon, the maximum adsorption capacity of $\mathrm{Cu}-\mathrm{AC}$ increased by $37.8 \%$. Additionally, through thermodynamic calculations the negative value of $\Delta G$ and positive value of $\Delta H$ showed that the adsorption was a spontaneous and endothermic process. All the above results reveal that $\mathrm{Cu}-\mathrm{AC}$ can be an effective absorbent for removing dyes from wastewater.

Received 8th January 2017 Accepted 23rd February 2017

DOI: $10.1039 / \mathrm{c} 7 \mathrm{ra00287d}$

rsc.li/rsc-advances membrane filtration, ${ }^{13,14}$ biosorption, ${ }^{15}$ and adsorption treatment ${ }^{16,17}$ have been used to treat wastewater. However, they are limited due to problems like high costs and long treatment times. Therefore, it is imperative to explore new methods that have low capital investments and environmental risks. ${ }^{18}$ Adsorption treatment is one of the most studied dye removal methods due to its high efficiency, green (nontoxic) components, low cost, and easy removal. ${ }^{19}$ Many adsorbents used in adsorption treatments including bio-sorbents, zeolites, nanoperfluorooctyl alumina, multiwalled carbon nanotubes, and cellulose-based wastes have been reported to decolorize wastewater. ${ }^{19,20}$ Many efforts have been devoted to designing different adsorbents for removing colored dyes and wastewater treatment; using a small amount of an adsorbent should be able to remove a large amount of dye. ${ }^{17,21}$ However, the adsorbents described above have some shortcomings such as low adsorption capacities or separating powers. ${ }^{19,22}$ Since activated carbon is one of the most used adsorbents with a porous structure, a huge specific surface area, and strong adsorption capacity, it is widely used for removal of organic dyes and pollutants from industrial wastewater. ${ }^{23-27}$ Activated carbon can adsorb many dyes with a high adsorption capacity, but its adsorption efficiency is low. To overcome these disadvantages, $\mathrm{Cu}-\mathrm{AC}$ as a potential high efficiency adsorbent was studied for treating wastewater with organic dyes in this paper. Because of the effect of photocatalytic degradation of copper, $\mathrm{Cu}-\mathrm{AC}$ can effectively
${ }^{a}$ State Key Laboratory of Complex Nonferrous Metal Resources Clean Utilization, Kunming University of Science and Technology, Kunming, Yunnan 650093, China. E-mail: hyxia@kmust.edu.cn

${ }^{5}$ Yunnan Provincial Key Laboratory of Intensification Metallurgy, Kunming University of Science and Technology, Kunming, Yunnan 650093, China

${ }^{c}$ National Local Joint Laboratory of Engineering Application of Microwave Energy and Equipment Technology, Kunming, Yunnan 650093, China

${ }^{d}$ Faculty of Metallurgical and Energy Engineering, Kunming University of Science and Technology, Kunming 650093, China 
improve the removal capacity for dyes. Ahmed M. Mansour et $a .^{28}$ reported that $\mathrm{CuO}$ nanoparticles exhibited good photocatalytic activity in degrading the industrial pollutant, methylene-blue.

Both conventional and microwave heating methods are commonly used to prepare activated carbon. ${ }^{29}$ Conventional methods are of limited used due to their slow heating rate and low energy efficiency. However, using microwave heating to prepare $\mathrm{Cu}-\mathrm{AC}$ can speed up the reaction rate and shorten reaction time because microwaves directly penetrate activated carbon, using the material inside to heat objects; thus, it is an internal molecular heating process which results in the temperature rising evenly both inside and outside of the material. ${ }^{30,31}$ Also, microwave heating leads to chemical bonds being vigorously vibrated and ruptured, which can result in copper being deposited on activated carbon. So, compared with traditional heating methods, microwave heating has a high efficiency. Shuheng Yao et al. $^{30}$ examined the effect of nitric acid modified activated carbon on removing $\mathrm{Pb}$ (II) in water under microwave heating and their results showed that modified activated carbon had a significant effect on the removal of $\mathrm{Pb}$ (II) from water.

The aim of the present work was to prepare $\mathrm{Cu}-\mathrm{AC}$ materials impregnated by cupric nitrate using microwave heating, and then test them for removing dyes in wastewater. Our method does not require costly and toxic precursors or a complicated procedure. Five kinds of dye wastewaters were adsorbed by $\mathrm{Cu}$ $\mathrm{AC}$ and $\mathrm{MB}$ was selected as a model organic pollutant used to assess adsorption with $\mathrm{Cu}-\mathrm{AC}$ samples under different preparation parameters to obtain the optimal parameters. In addition, this work also thoroughly studied the equilibrium, kinetics, and thermodynamics of the MB adsorption process. Thermodynamic parameters, such as $\Delta S, \Delta H$, and $\Delta G$, were calculated at the same time.

\section{Experimental}

\subsection{Experimental materials}

The material used for preparing $\mathrm{Cu}-\mathrm{AC}$ was powdered commercial activated carbon (CAC) purchased from a factory in Chengdu, China. All chemical reagents $\left(\mathrm{HCl}, \mathrm{Cu}\left(\mathrm{NO}_{3}\right)_{2}\right.$, etc.) used were analytical reagent grade purchased from a company in China. Rhodamine B, MB, Amaranth, Congo red and Eosin-Y molecular formulas are $\mathrm{C}_{28} \mathrm{H}_{31} \mathrm{ClN}_{2} \mathrm{O}_{3}, \mathrm{C}_{16} \mathrm{H}_{18} \mathrm{ClN}_{3} \mathrm{~S}, \mathrm{C}_{20} \mathrm{H}_{11^{-}}$ $\mathrm{N}_{2} \mathrm{Na}_{3} \mathrm{O}_{10} \mathrm{~S}_{3}, \mathrm{C}_{32} \mathrm{H}_{22} \mathrm{~N}_{6} \mathrm{Na}_{2} \mathrm{O}_{6} \mathrm{~S}_{2}$, and $\mathrm{C}_{20} \mathrm{H}_{6} \mathrm{Br}_{4} \mathrm{Na}_{2} \mathrm{O}$; respective molar weights are $479.01 \mathrm{~g} \mathrm{~mol}^{-1}, 319.85 \mathrm{~g} \mathrm{~mol}^{-1}, 604.47 \mathrm{~g}$ $\mathrm{mol}^{-1}, 696.68 \mathrm{~g} \mathrm{~mol}^{-1}$, and $691.85 \mathrm{~g} \mathrm{~mol}^{-1}$.

\subsection{Preparation of copper loaded activated carbon}

The carbon was washed with distilled water repeatedly until the effluent color was clear. The washed carbon was soaked in distilled water for $24 \mathrm{~h}$ and then filtered, after which it was soaked in aqueous $5 \% \mathrm{HCl}$ solution with constant shaking for another $24 \mathrm{~h}$ to further remove other impurities and dust particles. The acidic solution was then removed by filtration and the carbon further washed with distilled water. After being dried

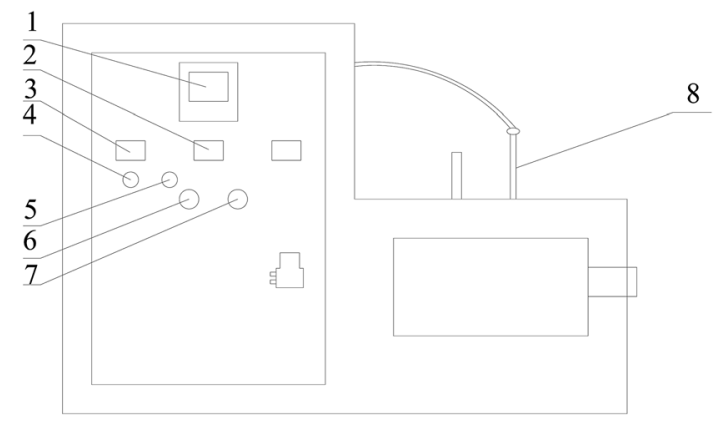

Fig. 1 Schematic of microwave heating equipment. (1) Temperature indicator, (2) current indicator, (3) voltage indicator, (4) hand regulator, (5) automatic regulator, (6) start button, (7) force close button, (8) thermocouple.

under vacuum at ambient temperature $\left(20^{\circ} \mathrm{C}\right), 10 \mathrm{~g}$ CAC aliquots were placed in $50 \mathrm{~mL}$ copper nitrate solutions with different concentrations to load copper ions on the activated carbon. Then, the suspensions were filtered and the samples were dried at $120{ }^{\circ} \mathrm{C}$ until a constant weight was obtained. Finally, the material was heated in a microwave furnace in the absence of any gas. The optimal preparation conditions of Cu-AC were: microwave temperature $800{ }^{\circ} \mathrm{C}$, microwave time $20 \mathrm{~min}$, microwave power $300 \mathrm{~W}$, and impregnation time $120 \mathrm{~min}$. The optimum conditions for adsorption of MB were established as: $150 \mathrm{~min}$ contact time, $\mathrm{pH}$ of 7 , and adsorbent dosage of $0.25 \mathrm{~g}$. As shown in Fig. 1, a continuous controllable microwave power was used for the experiments.

\subsection{Characterization of activated carbon}

The standard testing method of PR China (GB/T12496.10-1999) was used for measuring maximum adsorption capacity of $\mathrm{MB}$ with $\mathrm{Cu}-\mathrm{AC}$. The $\mathrm{N}_{2}$ adsorption and desorption isotherms of CAC and $\mathrm{Cu}-\mathrm{AC}$ were carried out at $77 \mathrm{~K}$ using an automatic adsorption apparatus (Autosorb-1-C, USA) with a relative pressure $\left(P / P_{0}\right)$ range from 0 to 1 . Scanning electron microscopy (SEM, Philips XL30ESEM-TMP) analysis was used to observe surface morphology and surface texture of the materials. EDS (Philips XL30ESEM-TMP) analysis was used to determine substance composition and element content. To study the changes of microstructures on activated carbon, an analysis was performed using a high-resolution X-ray diffraction (XRD) system (Philips PW1825). X-ray photoelectron spectroscopy (XPS) was performed with a PHI 5500 electron spectrometer (Physical Electronics, Inc., Chanhassen, MN, USA) using $200 \mathrm{~W} \mathrm{Mg}$ radiation. Fourier transform infrared spectroscopy (FTIR) was applied to qualitatively identify important chemical functional groups of $\mathrm{Cu}-\mathrm{AC}$ and CAC. FTIR spectra were obtained in the range 4000-400 $\mathrm{cm}^{-1}$ using an AVATAR 330 spectrophotometer (Thermo Fisher Scientific, USA). Raman analysis was recorded by a Ramascope System 1000 (Renishhwa, UK) spectroscopy.

\subsection{Adsorption experiments}

First, we chose five different dyes to test the adsorption performance of $\mathrm{Cu}-\mathrm{AC}$ : Rhodamine $\mathrm{B}, \mathrm{MB}$, Amaranth, Congo 
red, and Eosin-Y, respectively. MB and Rhodamine B showed a positive charge in solution as they are cationic dyes; Amaranth, Congo red, and Eosin-Y showed a negative charge in solution as they are anionic dyes. The concentration of all five dyes in this experiment was $400 \mathrm{mg} \mathrm{L}^{-1}$, and the $\mathrm{pH}$ values of them were: Rhodamine $\mathrm{B}(\mathrm{pH}=1-2), \mathrm{MB}(\mathrm{pH}=7-8)$, Amaranth $(\mathrm{pH}=3-4)$, Congo red $(\mathrm{pH}=4-5)$ and Eosin-Y $(\mathrm{pH}=5-6)$. In a series of typical experiments, $40 \mathrm{mg}$ of $\mathrm{Cu}-\mathrm{AC}$ was dispersed into $20 \mathrm{~mL}$ each of five dyes with a concentration of $400 \mathrm{mg} \mathrm{L}^{-1}$. From adsorption efficiency and characteristics, we choose MB to study adsorption kinetics, isotherms, and thermodynamics. Batch adsorption experiments were carried out using MB to test the adsorption potential capacity of $\mathrm{Cu}-\mathrm{AC}$. The experiments were conducted in a series of $250 \mathrm{~mL}$ volumetric flasks; we mixed $0.1 \mathrm{~g}$ of adsorbent with a $100 \mathrm{~mL}$ aliquot of the $\mathrm{MB}$ solution at various initial concentrations $(400,500,600$, and $800 \mathrm{mg} \mathrm{L}^{-1}$ ). The volumetric flasks were shaken in a gas bath thermostatic oscillator with a shaking speed of $300 \mathrm{rpm}$ until equilibrium was reached at three different temperatures (303 K, $313 \mathrm{~K}$, and $323 \mathrm{~K}$ ). When the adsorption equilibrium was reached, the amount of residual dye concentration was determined at $668 \mathrm{~nm}^{32}$ using a UV-vis spectrophotometer. The amounts of $\mathrm{MB}$ on an adsorbent $\left(q_{\mathrm{e}}\left(\mathrm{mg} \mathrm{g}^{-1}\right)\right)$ and removal efficiency $(R)$ were calculated at the equilibrium conditions from the following eqn (1) and (2), ${ }^{33}$ respectively:

$$
\begin{gathered}
q_{\mathrm{e}}=\left[\left(C_{0}-C_{\mathrm{e}}\right) V\right] / M \\
\text { Removal rate }(\%)=\left[\left(C_{0}-C_{t}\right) / C_{0}\right] \times 100 \%
\end{gathered}
$$

where $C_{0}\left(\mathrm{mg} \mathrm{L}^{-1}\right), C_{\mathrm{e}}\left(\mathrm{mg} \mathrm{L}^{-1}\right)$, and $C_{t}$ are the initial, equilibrium, and time $t$ concentrations of $\mathrm{MB}$, respectively. $V$ is the volume of the solution (L) and $M$ is the weight of the adsorbent $(\mathrm{g})$.

Kinetic models were used to determine the rate of the adsorption process besides providing valuable information

Table 1 The equations of kinetic and isotherm models

Equation

Kinetic models

Pseudo-first order

Pseudo-first order

$$
\frac{t}{q_{t}}=\frac{1}{k_{2} q_{\mathrm{e}}^{2}}+\frac{t}{q_{\mathrm{e}}}
$$

Isotherm models Freundlich

$$
\log q_{\mathrm{e}}=\log K_{\mathrm{f}}+\frac{1}{n} \log C_{\mathrm{e}}
$$

Langmuir

$$
q_{\mathrm{e}}=\frac{q_{\mathrm{m}} K_{\mathrm{L}} C_{\mathrm{e}}}{1+K_{\mathrm{L}} C_{\mathrm{e}}} ; \quad R_{\mathrm{L}}=\frac{1}{1+K_{\mathrm{L}} C_{0}}
$$

Temkin

$$
q_{\mathrm{e}}=A+B \ln C_{\mathrm{e}} ; \quad B=\frac{R \times T}{b}
$$

about reaction pathways. In this context, the kinetic models of pseudo-first order and pseudo-second order were investigated to understand the adsorption dynamics of $\mathrm{MB}$ on $\mathrm{Cu}-\mathrm{AC}$.

Adsorption isotherms were considered essential while determining the type of adsorption and the capacity of the adsorbent, since they provided information about the distribution of adsorbate between the liquid and solid phases at various equilibrium concentrations. Thus, the isotherm models of Freundlich, Langmuir, and Temkin were employed to assess the adsorption equilibrium characteristics of $\mathrm{MB}$ on $\mathrm{Cu}-\mathrm{AC}$.

All kinetic and isotherm models were fit to experimental data using their non-linear equations which are shown in Table 1.

\section{Results and discussion}

\subsection{Characterization of CAC and $\mathrm{Cu}-\mathrm{AC}$}

3.1.1. Pore structure analysis. The $\mathrm{N}_{2}$ adsorption-desorption isotherms, as well as the pore size distribution plots of CAC and $\mathrm{Cu}-\mathrm{AC}$, are shown in Fig. 2 and 3, respectively. According to the International Union of Pure and Applied Chemistry (IUPAC) classification, the isotherms of CAC and Cu-AC may be assigned as type IV; there is a hysteresis loop, which is a notable characteristic of a four type isotherm, and it will occur in a way similar to the adsorption of micropores (the isotherms will rise rapidly). The pore size distributions of CAC and $\mathrm{Cu}-\mathrm{AC}$ were analyzed by a DFT method and the specific surface areas of CAC and $\mathrm{Cu}-\mathrm{AC}$ were calculated by a BET mathematical model ${ }^{8}$ with the results presented in Table 2. The diameter of copper molecules is $0.257 \mathrm{~nm}$, and the average pore diameter of the CAC is $5.7322 \mathrm{~nm}$, so copper molecules can easily enter into the pores of the activated carbon. As the copper loaded onto activated carbon, it improved the performance of it. For example, CAC showed a $S_{\mathrm{BET}}$ of $1346 \mathrm{~m}^{2} \mathrm{~g}^{-1}$ and total pore volume of $0.847 \mathrm{~mL} \mathrm{~g}^{-1}$, while the $S_{\mathrm{BET}}$ of Cu-AC increased by $13.97 \%$ and total pore volume of $\mathrm{Cu}-\mathrm{AC}$ increased by $10.8 \%$. It is obvious that the adsorption capacity of the adsorbent is not only related to surface properties, but also to pore structure. As shown in Fig. 3, most of the pores fall into a mesoporous $(2-50 \mathrm{~nm})$ category. Kasaoka et $a l .{ }^{34}$ reported that adsorption occurred when the pore diameter of an adsorbent was at least 1.7 times as

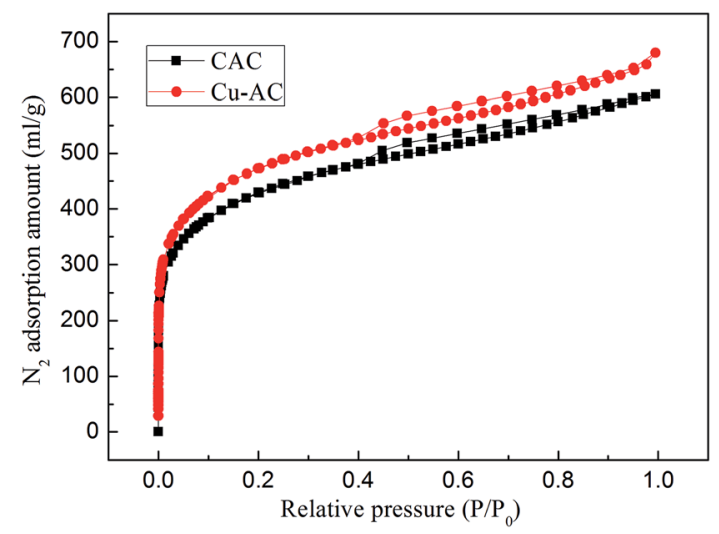

Fig. $2 \mathrm{~N}_{2}$ adsorption-desorption isotherms of the CAC and $\mathrm{Cu}-\mathrm{AC}$. 


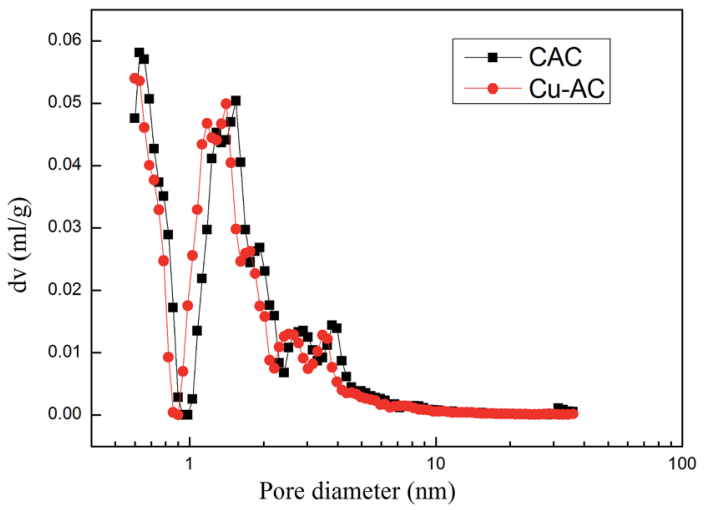

Fig. 3 Pore size distribution plots of $C A C$ and $C u-A C$.

Table 2 Surface physical characteristics of the CAC and $\mathrm{Cu}-\mathrm{AC}$

\begin{tabular}{lll}
\hline Characteristic & CAC & Cu-AC \\
\hline Specific surface area $\left(\mathrm{m}^{2} \mathrm{~g}^{-1}\right)$ & 1346 & 1534 \\
Total pore volume $\left(\mathrm{mL} \mathrm{g}^{-1}\right)$ & 0.8470 & 0.9385 \\
Average pore size $(\mathrm{nm})$ & 5.7322 & 5.7412
\end{tabular}

much as that of the adsorbate. The diameter of MB is about $0.8 \mathrm{~nm}$, while the average pore size of $\mathrm{Cu}-\mathrm{AC}$ is $5.7412 \mathrm{~nm}$; thus, it can effectively adsorb methylene blue molecules. ${ }^{35}$

3.1.2. XRD diffraction and XPS analysis. In order to study changes in the microstructures of $\mathrm{Cu}-\mathrm{AC}, \mathrm{X}$-ray diffraction (XRD) analysis was carried out to analyze CAC and $\mathrm{Cu}-\mathrm{AC}$. As shown in Fig. 4A, CAC mainly contains carbon and calcium carbonate (a part of the impurity not marked in Fig. 4A). As shown in Fig. 4B, XRD analysis of Cu-AC shows four broad diffraction peaks corresponding to four substances $(\mathrm{C}, \mathrm{CuO}, \mathrm{Cu}$, and $\mathrm{Cu}_{2} \mathrm{O}$, respectively).

Through analysis, the surface of activated carbon was determined to be mainly loaded with copper. Only a very small amount of copper oxides was formed on the surface of it; therefore, copper plays a main role in the adsorption process. Besides, compared with CAC, significant diffraction peaks of $\mathrm{Cu}$ or copper oxides were detected on the surface of $\mathrm{Cu}-\mathrm{AC}$, proving that cupric nitrate was successfully installed onto activated carbon and subsequently decomposed to copper oxides.

XPS is a technique widely used to determine the composition and structure of substances. The wide scan XPS spectrum of $\mathrm{Cu}-$ $\mathrm{AC}$ is shown in Fig. 4C, and it proves the existence of $\mathrm{Cu}, \mathrm{C}$, and O. Fig. $4 \mathrm{D}$ shows the $\mathrm{Cu} 2 \mathrm{p}_{3 / 2}$ and the $\mathrm{Cu} 2 \mathrm{p}_{1 / 2}$ spectrum region of $\mathrm{Cu}$ at peaks $932.8 \mathrm{eV}$ and $952 \mathrm{eV}$, respectively. Jinhyeong Kwon et al. ${ }^{36}$ reported the peak at $932.8 \mathrm{eV}$ indicates $\mathrm{Cu} 2 \mathrm{p}_{3 / 2}$ and the peak at $952.7 \mathrm{eV}$ indicates $\mathrm{Cu} 2 \mathrm{p}_{1 / 2}$. In most cases, the $\mathrm{Cu} 2 \mathrm{p}_{3 / 2}$ found indicated existence of oxides of copper and elemental copper. Fig. $4 \mathrm{E}$ shows the spectrum region of $\mathrm{O} 1 \mathrm{~s}$, which is resolved into three peaks. The binding energy of $\mathrm{Cu}-\mathrm{O}$ in the $\mathrm{O} 1 \mathrm{~s}$ band is $531.3 \mathrm{eV}$, which indicates the existence of copper oxide. ${ }^{37}$ The peak at $532.2 \mathrm{eV}$ is assigned the group of O$\mathrm{C}-\mathrm{O}$. Besides, a peak at $533.4 \mathrm{eV}$ was also observed, which is due to molecularly adsorbed $\mathrm{CO}_{2} \cdot{ }^{38}$ These conclusions were confirmed using XRD.

3.1.3. SEM and EDS analysis. A scanning electron micrograph (SEM) was used to evaluate the surface morphology and texture of materials before and after copper loading. Obviously, there is a great difference between the surface morphology of CAC and Cu-AC. Fig. 5 shows the SEM images of CAC (A), Cu-AC (B), and EDS for Cu-AC (C). As shown in Fig. 5A, CAC has abundant pore structures and the surface is smooth, which is suitable for copper ions to be loaded on the above. Fig. 5B displays the surface morphology of $\mathrm{Cu}-\mathrm{AC}$; it is clear that the white balls $\left(\mathrm{Cu}, \mathrm{Cu}_{2} \mathrm{O}\right.$, or $\left.\mathrm{CuO}\right)$ are evenly distributed on the surface of activated carbon, which changes the surface properties and thus leads to higher adsorption capacity. The EDS result shows that $\mathrm{Cu}-\mathrm{AC}$ has a certain content of $\mathrm{Cu}$ compounds (Fig. 5C) and these results are in good agreement with XRD, XPS, and SEM analysis.

3.1.4. FTIR analysis. The FTIR technique is an important tool to identify important functional groups present on the surface of materials which are capable of adsorbing organic pollutants. The FT-IR spectra of CAC and $\mathrm{Cu}-\mathrm{AC}$ are shown in Fig. 6; both spectra have similar shapes in vibration band characteristics of carbonaceous materials and the high intense bands between 3200 and $3500 \mathrm{~cm}^{-1}$ can be attributed to $\mathrm{O}-\mathrm{H}$ groups and $\mathrm{N}-\mathrm{H}$ stretching vibration. The band at about 2920 $\mathrm{cm}^{-1}$ identifies the stretching vibrations of aliphatic groups $-\mathrm{CH}_{2}-$. The bands at about 1500 and $1750 \mathrm{~cm}^{-1}$ can be assigned to $\mathrm{C}=\mathrm{O}$ axial deformation, such as highly conjugated $\mathrm{C}=\mathrm{O}$ stretching or $\mathrm{C}-\mathrm{O}$ stretching in carboxyl groups, respectively. Bands at about $1200 \mathrm{~cm}^{-1}$ can be attributed to C-O stretching of carboxylate and ether structures. Thus, there are abundant functional groups for adsorbing pollutant ions on activated carbon. These functional groups play a significant role in adsorption of contaminant ions. ${ }^{39}$

3.1.5. Raman analysis. Raman spectroscopy is a technique used to obtain information about molecular vibration or rotational energy of samples, and then identify a substance and analyze the nature of the material. Additionally, it is widely used to characterize structural features of carbonaceous materials. ${ }^{40,41}$ The Raman spectrum of CAC and $\mathrm{Cu}-\mathrm{AC}$ are shown in Fig. 7. These two spectra have obvious D and G bands, which appeared at approximately $1340 \mathrm{~cm}^{-1}$ (D band) and $1600 \mathrm{~cm}^{-1}$ ( $\mathrm{G}$ band); $\mathrm{D}$ and $\mathrm{G}$ bands are typical in spectra of carbon materials. Only CAC has D and G peaks in the entire spectral range. However, there are three peaks which appeared at approximately $160 \mathrm{~cm}^{-1}, 210 \mathrm{~cm}^{-1}$, and $620 \mathrm{~cm}^{-1}$ in Cu-AC. These indicate coexistence of a mixed phase (probably $\mathrm{Cu}_{2} \mathrm{O}$ mixed with $\mathrm{CuO}$ ). As proved by the $\mathrm{Cu}-\mathrm{AC}$ spectrum, it is due to coexistence of the $\mathrm{Cu}_{2} \mathrm{O}$ peak located near $615 \mathrm{~cm}^{-1}$ and the $\mathrm{CuO}$ phonon mode near $626 \mathrm{~cm}^{-1} \cdot{ }^{42,43}$ Comparing the two Raman spectra indicated that copper, with different oxides, was successfully loaded onto activated carbon. These results are consistent with those of XRD, XPS, and EDS.

3.1.6. Adsorption experiment. In a series of typical experiments, $40 \mathrm{mg}$ of $\mathrm{Cu}-\mathrm{AC}$ were dispersed into $20 \mathrm{~mL}$ each of five dyes with their concentrations at $400 \mathrm{mg} \mathrm{L}^{-1}$. The adsorption performance of $\mathrm{Cu}-\mathrm{AC}$ for five dyes is summarized in Fig. 8A. 

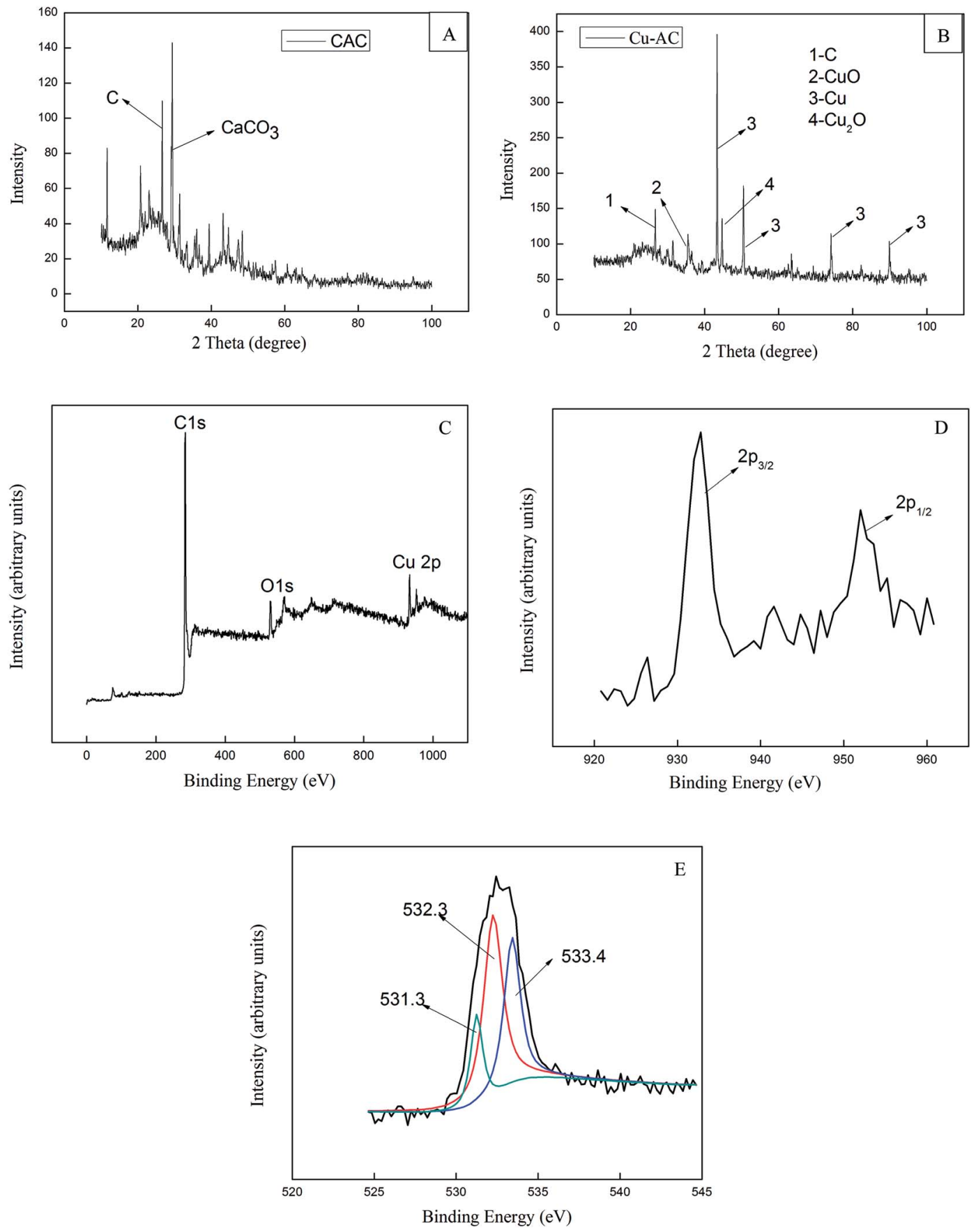

Fig. 4 XRD spectra of CAC (A), Cu-AC (B), the wide scan XPS spectrum of the Cu-AC (C), XPS of Cu-AC (D), and the peaks $O 1$ s of $C u-A C$ (E).

After $4 \mathrm{~h}$, the concentration of $\mathrm{MB}$, Congo red, and Eosin-Y almost decreased to zero. Conversely, the equilibrium concentration of Rhodamine B and amaranth was about $75.79 \mathrm{mg} \mathrm{L}^{-1}$ and $161.3 \mathrm{mg} \mathrm{L}^{-1}$, respectively. Cu-AC before and after adsorbing five dyes is show in Fig. $8 \mathrm{~B}$ and $\mathrm{C}$. It is seen from Fig. 8A that the adsorption capacity of $\mathrm{MB}$ is better than Rhodamine B, which are both cationic dyes. Therefore, according to the difference of adsorption capacity and adsorption characteristics, in order to study the adsorption mechanism of $\mathrm{Cu}-\mathrm{AC}$, we chose $\mathrm{MB}$ to study the adsorption kinetics, isotherms, and thermodynamics.
3.1.7. Adsorption mechanism. $\mathrm{N}_{2}$ adsorption-desorption isotherms curve, X-ray diffraction (XRD) analysis, and zeta potential were performed to research the adsorption mechanism. It is well known that the physical adsorption properties of $\mathrm{Cu}-\mathrm{AC}$ are determined by its physical properties (surface area and pore structure), and the electrostatic adherence of $\mathrm{Cu}-\mathrm{AC}$ is decided by its surface charge. ${ }^{\mathbf{4 4}}$ The specific surface area of CAC is $1346 \mathrm{~m}^{2} \mathrm{~g}^{-1}$ and adsorption capacity of MB on $\mathrm{CAC}$ is $202 \mathrm{mg} \mathrm{g}^{-1}$. However, the specific surface area of $\mathrm{Cu}-\mathrm{AC}$ is $1534 \mathrm{~m}^{2} \mathrm{~g}^{-1}$ and adsorption capacity of $\mathrm{MB}$ on $\mathrm{Cu}-\mathrm{AC}$ is $307.5 \mathrm{mg} \mathrm{g}^{-1}$. Before copper was loaded onto the surface of 

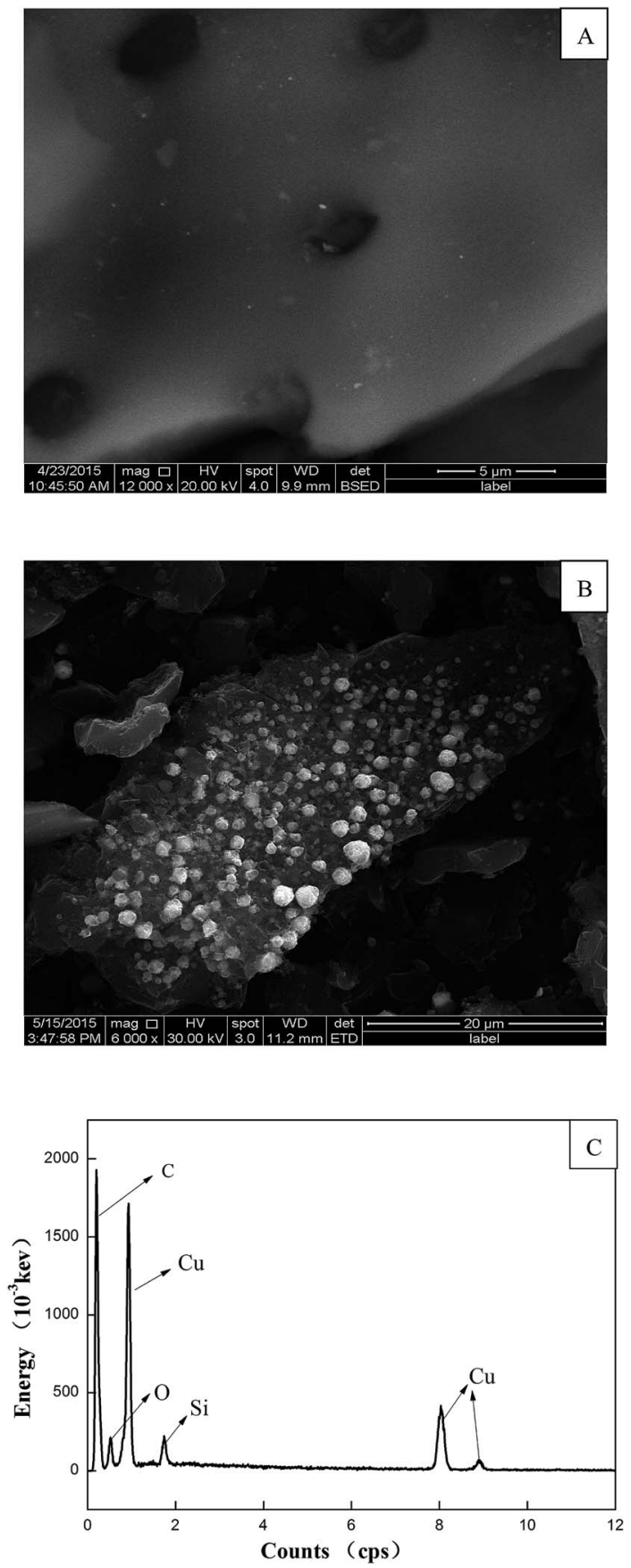

Fig. 5 SEM micrographs of CAC (A), Cu-AC (B), and EDS for Cu-AC (C).

CAC, its adsorption capacity was $202 \mathrm{mg} \mathrm{g}^{-1}$, and it increased by $105.5 \mathrm{mg} \mathrm{g}^{-1}$ after copper was loaded on CAC, thus proving that $\mathrm{MB}$ adsorption on $\mathrm{Cu}-\mathrm{AC}$ is mainly from physical adsorption. In order to verify the hypothesis of electrostatic adsorption, the surface charge of $\mathrm{Cu}-\mathrm{AC}$ in the solution was studied in different $\mathrm{pH}$ solutions and the results are shown in Fig. 9. The zeta potential of $\mathrm{Cu}-\mathrm{AC}$ shows positive potential in the range of $\mathrm{pH}<7$ and shows negative potential in the range of $\mathrm{pH}>7$. Therefore, in the range of $\mathrm{pH}<7$, there is repulsive interaction between $\mathrm{Cu}-\mathrm{AC}$ and positively charged dyes. Conversely, there is electrostatic adherence between $\mathrm{Cu}-\mathrm{AC}$

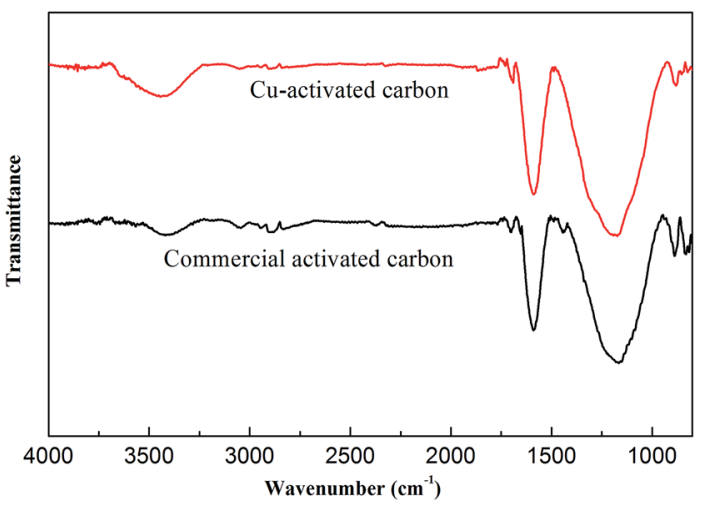

Fig. 6 Fourier transform infrared spectroscopy (FTIR) of commercial activated carbon and Cu-activated carbon.

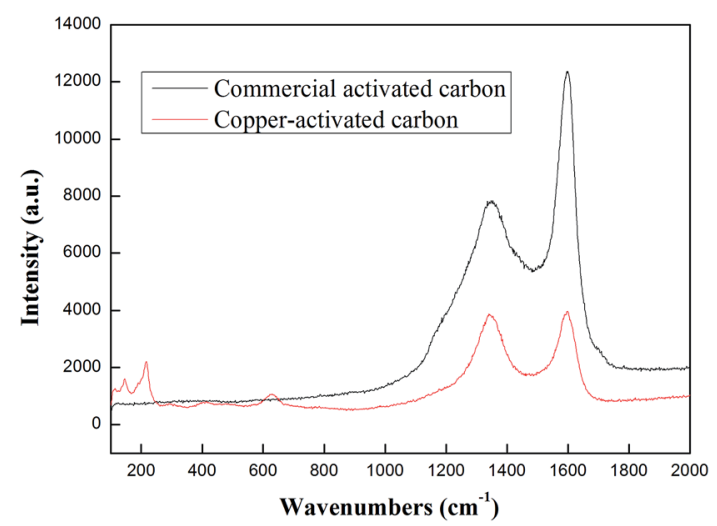

Fig. 7 Raman spectrum of commercial activated carbon and $\mathrm{Cu}$ activated carbon.

and negative charged dyes. Therefore, the MB solution shows it is positively charged and its $\mathrm{pH}$ is alkaline $(\mathrm{pH}=7-8)$; conversely, Cu-AC shows a negative charge in this case, so there is electrostatic adherence between $\mathrm{Cu}-\mathrm{AC}$ and $\mathrm{MB}$. The XRD showed that copper and a small amount of copper oxides were loaded on CAC after thermal decomposition of cupric nitrate; compared with $\mathrm{CAC}$, the adsorption capacity of $\mathrm{Cu}-\mathrm{AC}$ was increased. Therefore, copper and copper oxides play a catalytic role in the adsorption process, which is favorable for the adsorption of dyes on Cu-AC. And the photocatalytic degradation ability of copper has been proven in many literature references; for example, M. J. Ndolomingo and R. Meijboom $^{45}$ studied copper loaded on $\gamma-\mathrm{Al}_{2} \mathrm{O}_{3}$ for catalytic oxidation of methylene blue and Renu Sankar ${ }^{46}$ proved that copper oxide nanoparticles effectively degrade Coomassie brilliant blue R-250 dye under sunlight. Also, Ze Da Meng ${ }^{47}$ studied $\mathrm{Cu} / \mathrm{Cu}_{2} \mathrm{O}-\mathrm{AC} / \mathrm{TiO}_{2}$ photocatalytic degradation of methyl orange under visible light. Gao Xiaoyan ${ }^{48}$ studied $\mathrm{Cu}_{2} \mathrm{O}$ on activated carbon $\left(\mathrm{Cu}_{2} \mathrm{O} / \mathrm{AC}\right)$ catalyst for the photocatalytic degradation of pyrocatechol; they did a comparative experiment under dark and light conditions, and the results showed that copper caused photocatalytic degradation. We can see from this literature that copper has a catalytic effect on the removal of dyes, and the removal rate is higher with light. 
(A)
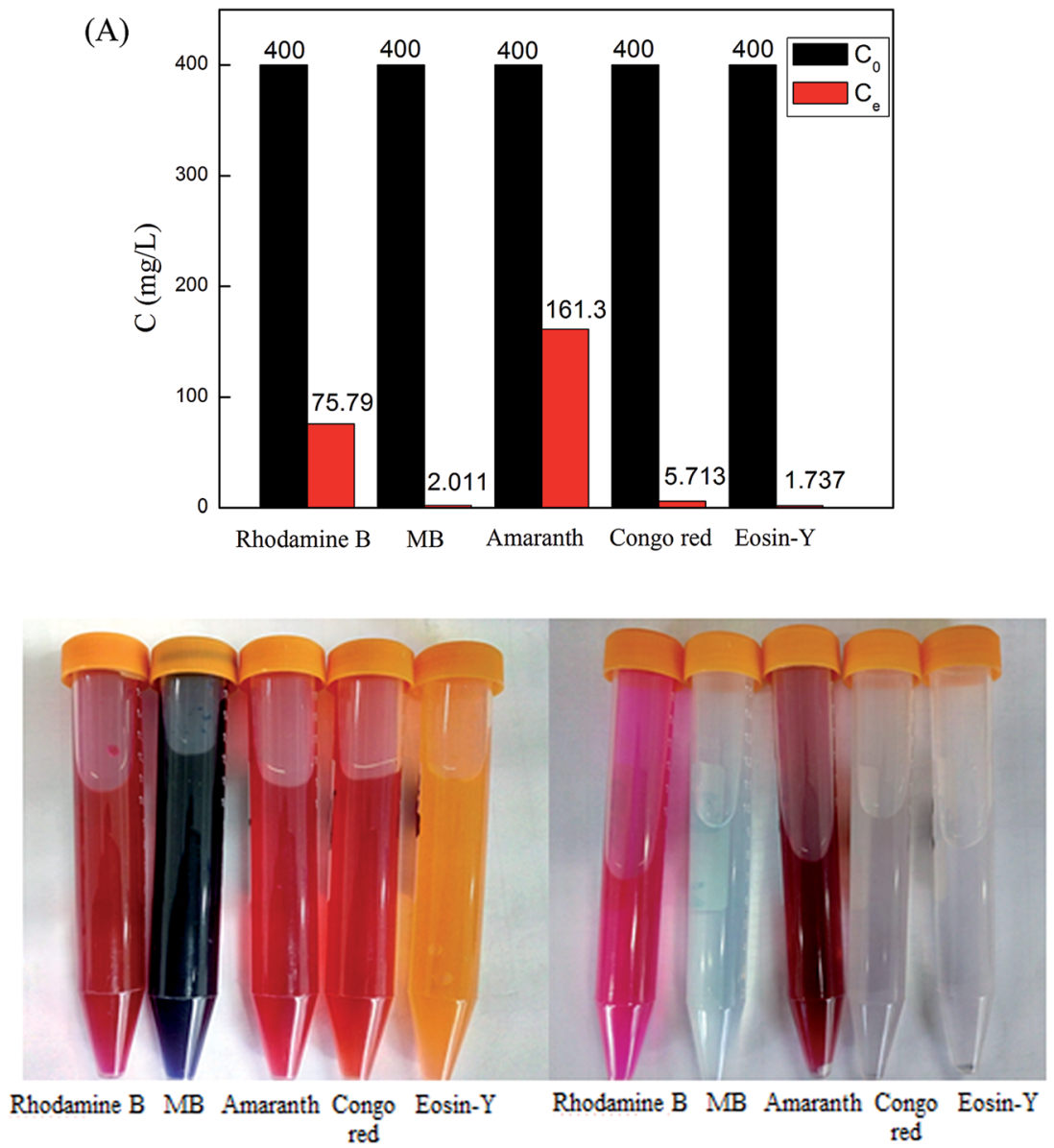

(B)

(C)

Fig. 8 The adsorption performance of $\mathrm{Cu}-\mathrm{AC}$ for five dyes: (A) picture of $\mathrm{Cu}-\mathrm{AC}$ before, (B) and after, (C) adsorbed five dyes.

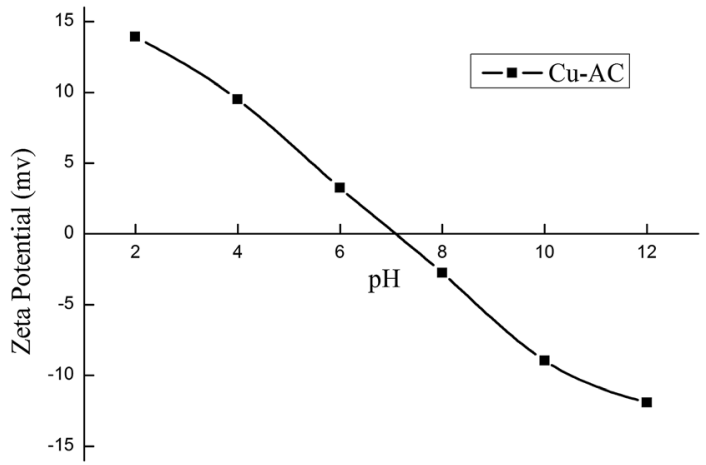

Fig. 9 The zeta potential of $\mathrm{Cu}-\mathrm{AC}$ at room temperature.

Therefore, copper plays a role in photocatalytic degradation of dyes.

\subsection{Adsorption isotherms}

The adsorption isotherm plays a vital role in describing the adsorption mechanism. When the adsorption process reaches an equilibrium state, it establishes how the molecules of an adsorbate are distributed between solid and liquid phases. Our adsorption experiments were conducted at various initial concentrations with different temperatures of 303,313 , and 323 $\mathrm{K}$. To determine the adsorption capacity of $\mathrm{Cu}-\mathrm{AC}$ to $\mathrm{MB}$, three widely used isotherm models (Langmuir, Freundlich, and Temkin) were used to determine which one was the best match with our experimental data. The three isotherm models data are shown in Table 3. Fig. 10-12 show the Langmuir, Freundlich, and Temkin isotherm plots respectively, for adsorption of $\mathrm{MB}$ on $\mathrm{Cu}$-AC. The results show that correlation $\left(R^{2}\right)$ with the Langmuir isotherm is larger (better) than with the other two isotherms. Hence, the Langmuir isotherm is the best and most appropriate for our experimental data. This implies a homogeneous and monolayer coverage of $\mathrm{MB}$ on the surface of $\mathrm{Cu}-\mathrm{AC}$. Moreover, another characteristic parameter of the Langmuir isotherm that can be used to evaluate the feasibility of adsorption on an adsorbent is a dimensionless factor $R_{\mathrm{L}}$, called the separation factor. It can be calculated by the following equation: ${ }^{49}$

$$
R_{\mathrm{L}}=\frac{1}{1+K_{\mathrm{L}} C_{0}}
$$

where $C_{0}$ corresponds to the initial concentration of $\mathrm{MB}$ and $K_{\mathrm{L}}$ is the Langmuir constant. The value of $R_{\mathrm{L}}$ is related to the type 
Table 3 Langmuir, Freundlich and Temkin constants for MB adsorption on samples at different temperature

\begin{tabular}{|c|c|c|c|}
\hline \multicolumn{4}{|c|}{ Langmuir coefficients } \\
\hline $\begin{array}{l}\text { Isotherm } \\
\text { constants }\end{array}$ & $q_{\max } /\left(\mathrm{mg} \mathrm{g}^{-1}\right)$ & $\begin{array}{l}K_{\mathrm{L}} /(\mathrm{L} \\
\left.\mathrm{mg}^{-1}\right)\end{array}$ & $R^{2}$ \\
\hline 302 & 360 & 24.76 & 0.999 \\
\hline 313 & 370 & 25.07 & 0.999 \\
\hline 323 & 373 & 32.63 & 0.999 \\
\hline
\end{tabular}

Freundlich coefficients

\begin{tabular}{llll}
$\begin{array}{l}\text { Isotherm } \\
\text { constants }\end{array}$ & $K_{\mathrm{F}} /\left(\mathrm{mg} \mathrm{g}^{-1}\right)$ & $1 / n$ & $R^{2}$ \\
\hline 303 & 14.76 & 0.0706 & 0.955 \\
313 & 14.89 & 0.0665 & 0.989 \\
323 & 15.09 & 0.0575 & 0.977 \\
\hline
\end{tabular}

Temkin coefficients

\begin{tabular}{llll}
$\begin{array}{l}\text { Isotherm } \\
\text { constants }\end{array}$ & $A\left(\mathrm{~L} \mathrm{mg}^{-1}\right)$ & $B\left(\mathrm{~J} \mathrm{mg}^{-1}\right)$ & $R^{2}$ \\
\hline 303 & 23.37 & 208.69 & 0.960 \\
313 & 22.58 & 221.66 & 0.985 \\
323 & 20.09 & 242.96 & 0.975
\end{tabular}

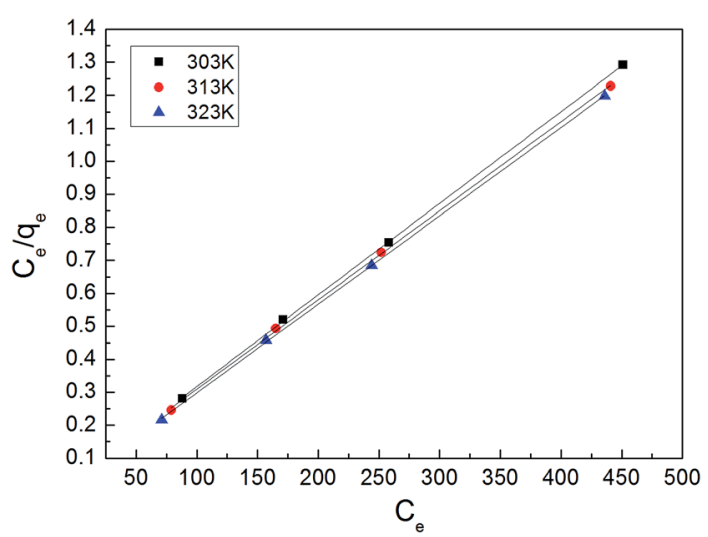

Fig. 10 Langmuir isotherm for MB removal using Cu-AC.

of isotherm: unfavorable $\left(R_{\mathrm{L}}>1\right)$, linear $\left(R_{\mathrm{L}}=1\right)$, favorable $(0<$ $\left.R_{\mathrm{L}}<1\right)$, and irreversible $\left(R_{\mathrm{L}}=0\right)$. In this work, the $R_{\mathrm{L}}$ values of the $\mathrm{MB}$ adsorption were calculated to be in the range of $0.1717-$ 0.5831 , indicating that $\mathrm{MB}$ adsorption onto $\mathrm{Cu}-\mathrm{AC}$ is favorable.

\subsection{Adsorption kinetics}

The adsorption rate is a vital parameter as it helps determine the applicability of an adsorption mechanism and also provides useful information for designing the experimental process. Many applications including production of a decoloring process, wastewater treatment, and organic pollution removal need a rapid adsorption rate and short adsorption time. A pseudo first-order model and pseudo second-order model were

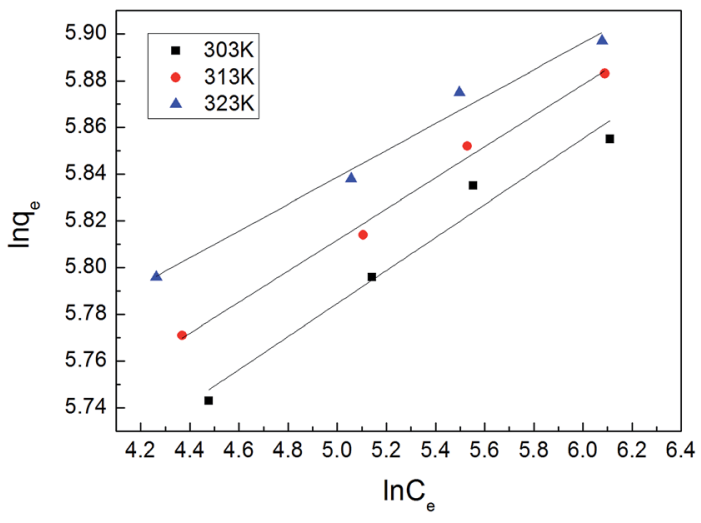

Fig. 11 Freundlich isotherm for MB removal using Cu-AC.

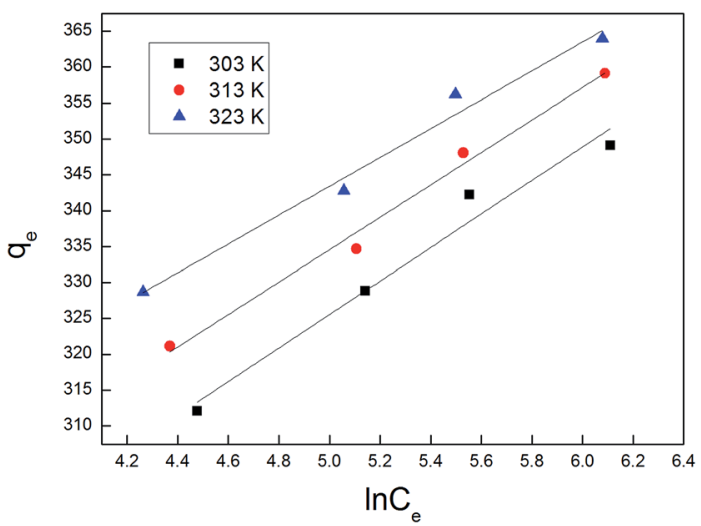

Fig. 12 Temkin isotherm for MB removal using $\mathrm{Cu}-\mathrm{AC}$.

applied to help understand the adsorption kinetics. The best fitting model was selected based on the linear regression correlation coefficient $R^{2}$. Therefore, it was necessary to determine which model is most suitable for our experimental data. The results of the parameter data of the two models are calculated and summarized in Table 4, which helped us predict the adsorption rate and obtain much important information for the design and modeling processes. Fig. 13 and 14 show two model plots and the constants $\left(k_{1}, k_{2}\right)$ and $q_{\mathrm{e}}$ were determined using the slope and intercept of these plots, respectively. As shown in Table 4, the pseudo first-order model has the lower $R^{2}$ values, and the experimental data is consistent with the pseudo secondorder kinetic model with a $R^{2}$ value close to 1 .

\subsection{Adsorption thermodynamics}

Thermodynamic parameters such as entropy $(\Delta S)$, enthalpy $(\Delta H)$, and free energy $(\Delta G)$ were obtained by the following equations.

$$
\begin{gathered}
K_{\mathrm{D}}=\frac{q_{\mathrm{e}} W}{C_{\mathrm{e}} V} \\
\Delta G^{\theta}=-R T \ln K \\
\Delta G^{\theta}=\Delta H^{\theta}-T \Delta H^{\theta} \\
\ln K_{\mathrm{D}}=\frac{\Delta S^{\theta}}{R}-\frac{\Delta H^{\theta}}{R T}
\end{gathered}
$$


Table 4 Kinetic parameters of pseudo first-order model and pseudo second-order model for MB adsorption

\begin{tabular}{|c|c|c|c|c|c|c|c|}
\hline$C_{0} /\left(\mathrm{mg} \mathrm{L}^{-1}\right)$ & $q_{\mathrm{e}, \exp } /\left(\mathrm{mg} \mathrm{g}^{-1}\right)$ & \multicolumn{3}{|c|}{ Pseudo-first order model } & \multicolumn{3}{|c|}{ Pseudo-second order model } \\
\hline 500 & 329 & 0.0206 & 89 & 0.9491 & 0.000358 & 341 & 0.9986 \\
\hline 600 & 342 & 0.0261 & 122 & 0.9869 & 0.000343 & 355 & 0.9989 \\
\hline 800 & 349 & 0.0229 & 100 & 0.9811 & 0.000336 & 361 & 0.9991 \\
\hline
\end{tabular}

Parameters such as $\Delta H$ and $\Delta S$ for $\mathrm{MB}$ can be determined from the slope and intercept of a van't Hoff plot of $\ln K_{\mathrm{D}}$ versus $1 / T$ as shown in Fig. 15 and Table 5. The values of $\Delta G$ were calculated from eqn (5) at different temperatures. The values of $\Delta G$ are found to be negative at $303 \mathrm{~K}, 313 \mathrm{~K}$, and $323 \mathrm{~K}$, indicating that the adsorption is a spontaneous process. The decrease in the negative value of $\Delta G$ with increasing temperature indicates that the adsorption of $\mathrm{MB}$ molecules is easier at higher temperatures. ${ }^{50}$ The positive values of $\Delta H$ indicate that the adsorption process substantiates physisorption and the adsorption reaction is an endothermic nature of MB adsorption, based on $\Delta H$ less than 80 $\mathrm{kJ} \mathrm{mol}^{-1}$. Meanwhile, the positive $\Delta S$ suggested the affinity of activated carbon for MB and increasing randomness at the solidsolution interface during the adsorption process. In addition,

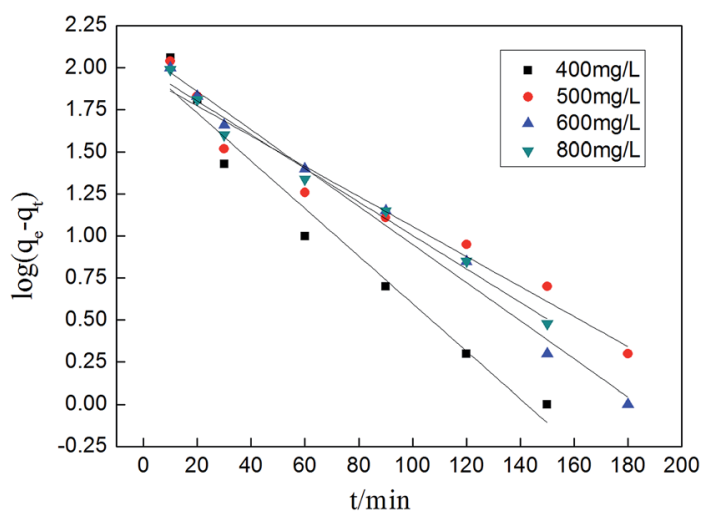

Fig. 13 Pseudo first-order plot for MB removal using Cu-AC.

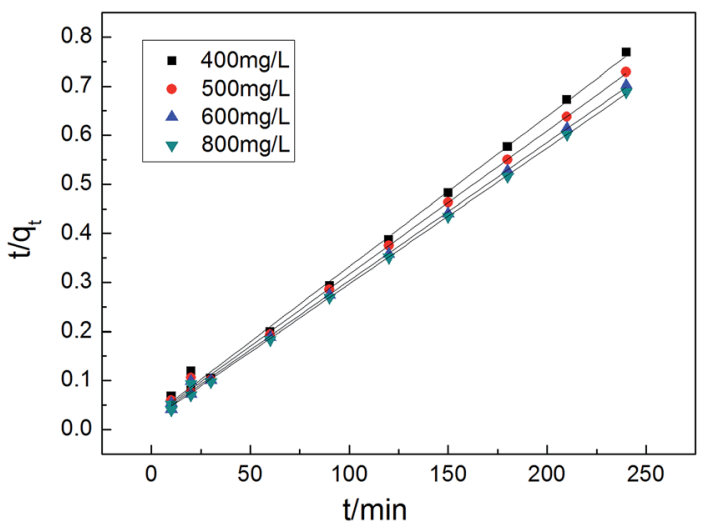

Fig. 14 Pseudo second-order plot for MB removal using $\mathrm{Cu}-\mathrm{AC}$. some structural properties changed in the adsorbates and adsorbents.

\subsection{Comparison of present study with previous studies}

The MB removal process using various adsorbents has been studied by many scholars, and the removal of $\mathrm{MB}$ using $\mathrm{Cu}-\mathrm{AC}$ adsorbent is investigated in the present work. The results for

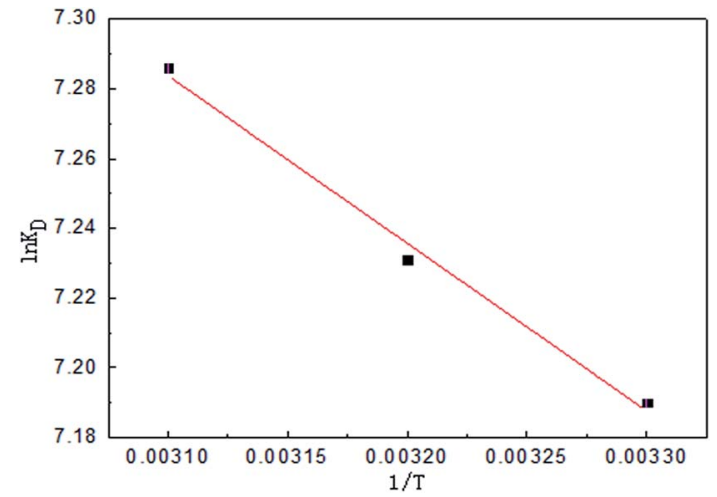

Fig. 15 Van't Hoff plot of MB in an adsorption solution of $\mathrm{Cu}-\mathrm{AC}$.

Table 5 Thermodynamic parameters for adsorption of MB on $\mathrm{Cu}-\mathrm{AC}$

\begin{tabular}{lllll}
\hline$T /(\mathrm{K})$ & $\begin{array}{l}K_{\mathrm{D}} / \\
(\mathrm{mL} \mathrm{g})\end{array}$ & $\begin{array}{l}\Delta G^{\theta} / \\
\left(\mathrm{kJ} \mathrm{mol}^{-1}\right)\end{array}$ & $\begin{array}{l}\Delta H^{\theta} / \\
\left(\mathrm{kJ} \mathrm{mol}^{-1}\right)\end{array}$ & $\begin{array}{l}\Delta S^{\theta} / \\
\left(\mathrm{J}(\mathrm{mol} \mathrm{K})^{-1}\right)\end{array}$ \\
\hline 303 & 1326 & -18.112 & & \\
313 & 1381 & -18.816 & 3.99 & 72.93 \\
323 & 1459 & -19.565 & &
\end{tabular}

Table 6 Summary of present work done using $\mathrm{Cu}$-AC for removal of $\mathrm{MB}$ and comparison with previous studies

\begin{tabular}{|c|c|c|c|}
\hline Adsorbents & Adsorbate & $\begin{array}{l}\text { Maximum adsorption } \\
\text { capacity }\left(\mathrm{mg} \mathrm{g}^{-1}\right)\end{array}$ & References \\
\hline $\mathrm{Cu}-\mathrm{AC}$ & MB & 373 & This work \\
\hline Ordinary AC & MB & 232 & This work \\
\hline CuO-NP-AC & MB & 10.55 & 51 \\
\hline Ag-NP-AC & MB & 71.43 & 52 \\
\hline Pd-NP-AC & MB & 75.40 & 53 \\
\hline Fe-activated carbon & MB & 259.74 & 35 \\
\hline ZnS:Cu-NP-AC & MB & 123.46 & 53 \\
\hline NiS-NP-AC & MB & $46-52$ & 54 \\
\hline $\mathrm{Fe}_{3} \mathrm{O}_{4} @ G P T M S @ L y s$ & MB & 185 & 55 \\
\hline
\end{tabular}


MB removal reported in the literature are summarized in Table 6. It can be seen that the adsorption capacity of $\mathrm{Cu}-\mathrm{AC}$ increases remarkably, indicating that copper loading increased its adsorption capacity through the photocatalytic degradation ability of copper oxide. And comparing $\mathrm{Cu}-\mathrm{AC}$ with ordinary AC showed that the maximum adsorption capacity of $\mathrm{Cu}-\mathrm{AC}$ was increased by $141 \mathrm{mg} \mathrm{g}^{-1}$.

\section{Conclusion}

Removal of $\mathrm{MB}$ was investigated using $\mathrm{Cu}-\mathrm{AC}$ with wastewater. An adsorption experiment was carried out using $\mathrm{Cu}-\mathrm{AC}$ prepared by microwave heating and its adsorption capacity was determined by the adsorption of MB. The adsorption process fits a pseudo second-order model, which suggests that the adsorption rate is more dependent on the availability of adsorption sites than on dye concentration. And, equilibrium data fit the Langmuir isotherm model, indicating monolayer coverage of MB molecules over the surface of Cu-AC. The Langmuir maximum adsorption capacity was $373 \mathrm{mg} \mathrm{g}^{-1}$. And, comparing $\mathrm{Cu}-\mathrm{AC}$ with ordinary AC activity shows that its maximum adsorption capacity was greatly improved. Thermodynamic parameters $(\Delta S, \Delta H$, and $\Delta G)$ show that the physical adsorption process is endothermic and spontaneous. According to our experiments and characterization analysis, adsorption of methylene blue on copper activated carbon is primarily from physical adsorption and some electrostatic adsorption; also, copper loading on activated carbon plays a catalytic role. Based on all results, $\mathrm{Cu}-\mathrm{AC}$ can be regarded as a potential adsorbent for the removal of methylene blue dye from aqueous solutions.

\section{Acknowledgements}

The authors would like to express their gratitude to the Specialized Research Fund for the National Natural Science Foundation of China (51504119, 21567013), National high technology research and development plan (2015AA020201, 863 Program), Yunnan Applied Basic Research Project (2015FB129), the Yunnan Provincial Science and Technology Innovation Talents Scheme Technological Leading Talent (2013HA002), and Extracurricular Science and Technology Innovation Fund Project of Kunming University of Science and Technology (2015YB004).

\section{References}

1 M. Ibrahim, A. A. Shaltout, D. E. Atta, A. F. Jalbout and M. Soylak, J. Iran. Chem. Soc., 2009, 6(2), 364-372.

2 I. M. Ismail, A. S. Fawzy, N. M. Abdel-Monem, M. H. Mahmoud and M. A. El-Halwany, J. Adv. Res., 2012, 3, 331-336.

3 M. Ghaedi, A. G. Nasab, S. Khodadoust, R. Sahraei and A. Daneshfar, J. Ind. Eng. Chem., 2015, 21, 986-993.

4 P. K. Gautam, R. K. Gautam, S. Banerjee, G. Lofrano, M. A. Sanroman, M. C. Chattopadhyaya and J. D. Pandey, J. Environ. Chem. Eng., 2015, 3, 2560-2568.

5 R. M. M. El-Kilani and M. H. Belal, J. Adv. Res., 2010, 1, 243253.
6 A. Mirzaei, A. Ebadi and P. Khajavi, Chem. Eng. J., 2013, 231, 550-560.

7 Z. N. Liu, A. N. Zhou, G. R. Wang and X. G. Zhao, Chin. J. Chem. Eng., 2009, 17, 942-948.

8 M. Ghaedi, M. Ghayedi, S. N. Kokhdan, R. Sahraei and A. Daneshfar, J. Ind. Eng. Chem., 2013, 19, 1209-1217.

9 O. Tünay, I. Kabdasli, G. Eremektar and D. Orhon, Water Sci. Technol., 1996, 34, 9-16.

10 E. Forgacsa, T. Cserhátia and G. Oros, Environ. Int., 2004, 30, 953-971.

11 Q. Q. Zhai, T. Bo and G. X. Hu, J. Hazard. Mater., 2011, 198, 78-86.

12 A. R. Tehrani-Bagha, N. M. Mahmoodi and F. M. Menger, Desalination, 2010, 260(1-3), 34-38.

13 E. Alventosa-deLara, S. Barredo-Damas, M. I. AlcainaMiranda and M. I. Iborra-Clar, J. Hazard. Mater., 2012, 209-210, 492-500.

14 T. Robinson, G. McMullan, R. Marchant and P. Nigam, Bioresour. Technol., 2001, 77, 247-255.

15 M. Ghaedi, S. Hajati, B. Barazesh, F. Karimi and G. Ghezelbash, J. Ind. Eng. Chem., 2013, 19, 227-233.

16 C. Leodopoulos, D. Doulia, K. Gimouhopoulos and T. M. Triantis, Appl. Clay Sci., 2012, 70, 84-90.

17 A. Asfaram, M. Ghaedi, S. Hajati, A. Goudarzi and A. A. Bazrafshan, Spectrochim. Acta, Part A, 2015, 145, 203-212.

18 M. R. Awual, I. M. M. Rahman, T. Yaita, M. A. Khaleque and M. Ferdows, Chem. Eng. J., 2014, 236, 100-109.

19 T. Jiang, Y. D. Liang, Y. J. He and Q. Wang, J. Environ. Chem. Eng., 2015, 3, 1740-1751.

20 A. Mirzaei, A. Ebadi and P. Khajavi, Chem. Eng. J., 2013, 231, 550-560.

21 M. Aut and B. H. Hameed, J. Ind. Eng. Chem., 2013, 19, 11531161.

22 D. Morshedi, Z. Mohammadi, M. M. A. Boojar and F. Aliakbari, Colloids Surf., B, 2013, 112, 245-254.

23 S. L. Liu, Y. N. Wang and K. T. Lu, J. Porous Mater., 2014, 21, 459-466.

24 J. M. V. Nabais, C. Laginhas, M. M. L. R. Carrott, P. J. M. Carrott, J. E. C. Amorós and A. V. N. Gisbert, Appl. Surf. Sci., 2013, 15, 919-924.

25 A. Policicchioa, E. Maccallinia, R. G. Agostinoa, F. Ciuchib, A. Aloisec and G. Giordanoc, Fuel, 2013, 104, 813-821.

26 B. Meryemoglu, S. Irmak, A. Hesenov and O. Erbatur, Int. J. Hydrogen Energy, 2012, 37, 17844-17852.

27 E. Kacen and C. Kutahyali, J. Anal. Appl. Pyrolysis, 2012, 97, 149-157.

28 A. M. Mansour, E. M. El Bakry and N. T. Abdel-Ghani, J. Photochem. Photobiol., A, 2016, 327, 21-24.

29 M. J. Ahmed, J. Environ. Chem. Eng., 2016, 4, 89-99.

30 S. H. Yao, J. J. Zhang, D. K. Shen, R. Xiao, S. Gu, M. Zhao and J. Y. Liang, J. Colloid Interface Sci., 2016, 463, 118-127.

31 A. Kundu, B. S. Gupta, M. A. Hashim and G. Redzwan, J. Cleaner Prod., 2015, 105, 420-427.

32 A. Asfaram, M. Ghaedi, S. Hajati, A. Goudarzi and A. A. Bazrafshan, Spectrochim. Acta, Part A, 2015, 145, 203212. 
33 M. Ghaedi, A. M. Ghaedi, M. Hossainpour, A. Ansari, M. H. Habibi and A. R. Asghari, J. Ind. Eng. Chem., 2014, 20, 1641-1649.

34 S. Kasaoka, Y. Sakata, E. Tanaka and R. Naitoh, Int. Chem. Eng., 1989, 29, 734-742.

35 S. Cheng, L. B. Zhang, H. Y. Xia, J. H. Peng, J. H. Shu and C. Y. Li, RSC Adv., 2016, 6, 78936-78946.

36 J. Kwon, S. Park, T. H. Lee, J.-M. Yang and C. S. Lee, Appl. Surf. Sci., 2011, 257, 5115-5120.

37 S. P. Chenakin, R. Szukiewicz, R. Barbosa and N. Kruse, J. Electron Spectrosc. Relat. Phenom., 2016, 209, 66-77.

38 Y. F. Xi, Z. M. Sun, T. Hreid, G. A. Ayoko and R. L. Frost, Chem. Eng. J., 2014, 247, 66-74.

39 M. Ahmaruzzaman and V. K. Gupta, Ind. Eng. Chem. Res., 2011, 50, 13589-13613.

40 A. Sadezky, H. Muckenhuber, H. Grothe, R. Niessner and U. Pöschl, Carbon, 2005, 43, 1731-1742.

41 X. Xu, W. Song, D. G. Huang, B. Y. Gao, Y. Y. Sun, Q. Y. Yue and K. F. Fu, Colloids Surf., A, 2015, 476, 68-75.

42 M. H. Chou, S. B. Liu, C. Y. Huang, S. Y. Wu and C. L. Cheng, Appl. Surf. Sci., 2008, 254, 7539-7543.

43 T. H. Tran and V. T. Nguyen, Mater. Sci. Semicond. Process., 2016, 46, 6-9.

44 L. B. Zhang, Y. H. Liu, S. X. Wang, B. G. Liu and J. H. Peng, RSC Adv. , 2015, 99618-99626.
45 M. J. Ndolomingo and R. Meijboom, Appl. Catal., A, 2014, 33-43.

46 R. Sankar, P. Manikandan, V. Malarvizhi, T. Fathima, K. S. Shivashangari and V. Ravikumar, Spectrochim. Acta, Part A, 2014, 746-750.

47 Z. D. Meng, T. Ghosh, J. H. Cho, L. Zhu, C. Y. Park, J. G. Choi and W. C. Oh, J. Korean Ceram. Soc., 2011, 571-576.

48 X. Y. Gao, X. J. Zhang, Y. C. Tang, Y. B. Huang, Y. Zhang and Y. Q. Zi, Kinet. Catal., 2011, 672-677.

49 H. Gupta and P. R. Gogate, Ultrason. Sonochem., 2016, 30, 113-122.

50 P. K. Gautam, R. K. Gautam, R. S. Saroj and J. D. Pandey, Proc. Natl. Acad. Sci., India, Sect. A, 2015, 85, 35-39.

51 M. Ghaedi, A. M. Ghaedi, M. Hossainpour, A. Ansari, M. H. Habibi and A. R. Asghari, J. Ind. Eng. Chem., 2014, 20, 1641-1649.

52 K. Mahapatra, D. S. Ramteke and L. J. Paliwal, J. Anal. Appl. Pyrolysis, 2012, 95, 79-86.

53 A. Asfaram, M. Ghaedi, S. Hajati, A. Goudarzi and A. A. Bazrafshan, Spectrochim. Acta, Part A, 2015, 145, 203212.

54 M. Ghaedi, M. Pakniat, Z. Mahmoudi, S. Hajati, R. Sahraei and A. Daneshfar, Spectrochim. Acta, Part A, 2014, 123, 402409.

55 Y. R. Zhang, S. L. Shen, S. Q. Wang, J. Huang, P. Su, Q. R. Wang and B. X. Zhao, Chem. Eng. J., 2014, 239, 250-256. 